\title{
A chimeric haemagglutinin-based influenza split virion vaccine adjuvanted with AS03 induces protective stalk-reactive antibodies in mice
}

\author{
Raffael Nachbagauer ${ }^{1,2}$, David Kinzler ${ }^{1,3}$, Angela Choi ${ }^{1,4}$, Ariana Hirsh ${ }^{1}$, Edith Beaulieu ${ }^{5,9}$, Nicolas Lecrenier ${ }^{6}$, Bruce L Innis ${ }^{7}$, \\ Peter Palese ${ }^{1,8}$, Corey $\mathrm{P}$ Mallett ${ }^{5}$ and Florian Krammer ${ }^{1}$
}

\begin{abstract}
Seasonal influenza virus vaccines are generally effective at preventing disease, but need to be well matched to circulating virus strains for maximum benefit. Influenza viruses constantly undergo antigenic changes because of their high mutation rate in the immunodominant haemagglutinin (HA) head domain, which necessitates annual re-formulation and re-vaccination for continuing protection. In case of pandemic influenza virus outbreaks, new vaccines need to be produced and quickly distributed. Novel influenza virus vaccines that redirect the immune response towards more conserved epitopes located in the HA stalk domain may remove the need for annual vaccine re-formulation and could also protect against emergent pandemic strains to which the human population is immunologically naive. One approach to create such universal influenza virus vaccines is the use of constructs expressing chimeric HAs. By sequential immunization with vaccine strains expressing the same conserved HA stalk domain and exotic HA heads to which the host is naive, antibodies against the stalk can be boosted to high titres. Here we tested a monovalent chimeric HA-based prototype universal influenza virus split virion vaccine candidate with and without AS03 adjuvant in primed mice. We found that the chimeric HA-based vaccination regimen induced higher stalk antibody titres than the seasonal vaccine. The stalk antibody responses were long lasting, cross-reactive to distantly related HAs and provided protection in vivo in a serum transfer challenge model. The results of this study are promising and support further development of a universal influenza vaccine candidate built on the chimeric HA technology platform.
\end{abstract}

Npj Vaccines (2016) 1, 16015; doi:10.1038/npjvaccines.2016.15; published online 22 September 2016

\section{INTRODUCTION}

Current seasonal influenza virus vaccines show high vaccine efficacy when they are well matched with circulating virus strains. ${ }^{1}$ However, influenza viruses constantly change their surface glycoproteins that are the targets of most immune responses, which allows them to escape pre-existing immunity, a process called antigenic drift. ${ }^{2}$ Therefore, head-based seasonal influenza virus vaccines have to be re-formulated and re-administered on an annual basis. ${ }^{3}$ In addition, novel viruses can appear at irregular intervals and cause influenza virus pandemics that can claim millions of lives. ${ }^{4}$ Unfortunately, current seasonal influenza virus vaccines are unlikely to protect against future pandemic viruses. Protection from influenza viruses is usually correlated with antibodies that bind to the membrane distal head domain of the haemagglutinin molecule (HA) and inhibit the haemagglutination function (haemagglutination inhibition activity), thereby blocking the virus from attaching to host cell receptors. ${ }^{5}$ However, the head domain has a high plasticity and it is the main site of antigenic drift. ${ }^{6,7}$ The stalk domain is, in contrast to the head domain, relatively conserved but immuno-subdominant (possibly related to lower accessibility of this domain). Several strategies have been developed, which induce broad protection against influenza viruses, overcoming the limitations of currently licensed seasonal vaccines. ${ }^{8-18}$ One of these approaches aims at redirecting the immune response away from the immuno-dominant head domain of the viral HA and towards the more conserved and immuno-subdominant stalk domain using chimeric HAs (cHAs). 8,19,20 The cHAs are combinations of 'exotic' head domains, mostly from avian influenza virus subtypes to which humans are naive, paired with a conserved stalk domain (e.g., from $\mathrm{H} 1$ or $\mathrm{H} 3$ $\mathrm{HAs})^{21,22}$ Sequential immunization with $\mathrm{cHAs}$ that have different head domains but the same stalk domain can break the immunodominance of the head and re-direct the immune response towards the conserved stalk domain (Figures 1a and b). This principle has been demonstrated with experimental vaccines based on recombinant proteins or viral vectors in mice and ferrets. ${ }^{8,19,20}$ Here we assessed whether the same principle holds true using split-vaccine cHAs produced in a pilot process for commercial vaccine production in combination with $\mathrm{ASO}_{3}$ adjuvant, a component of a licensed $\mathrm{H} 5 \mathrm{~N} 1$ pandemic influenza virus vaccine. This work is a necessary precursor to evaluation of the same vaccine strategy in human subjects.

\footnotetext{
${ }^{1}$ Department of Microbiology, Icahn School of Medicine at Mount Sinai, New York, NY, USA; ${ }^{2}$ Faculty of Life Sciences, University of Vienna, Vienna, Austria; ${ }^{3}$ Institute of Molecular Virology, Center of Molecular Biology of Inflammation, University of Münster, Münster, Germany; ${ }^{4}$ Graduate School of Biological Sciences, Icahn School of Medicine at Mount

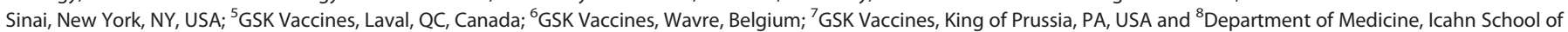
Medicine at Mount Sinai, New York, NY, USA.

Correspondence: CP Mallett or F Krammer (corey.p.mallett@gsk.com or florian.krammer@mssm.edu)

${ }^{9}$ Current address: NEOMED LABS, Laval, QC, Canada.

Received 17 May 2016; revised 10 July 2016; accepted 20 July 2016
} 


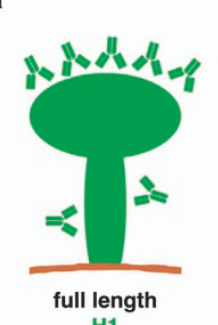

H1

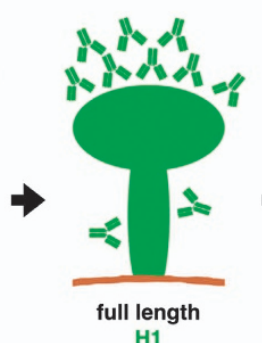

H1

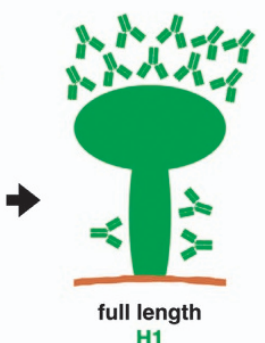

H1 b

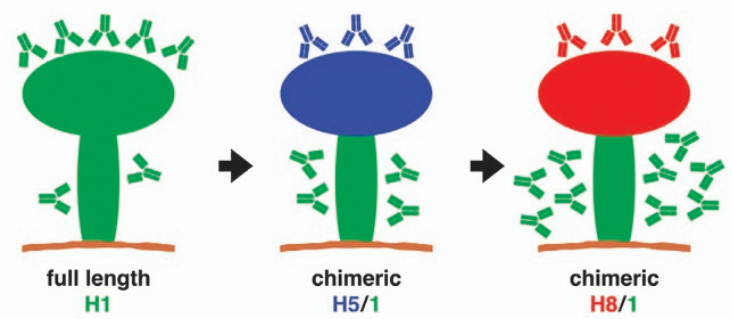

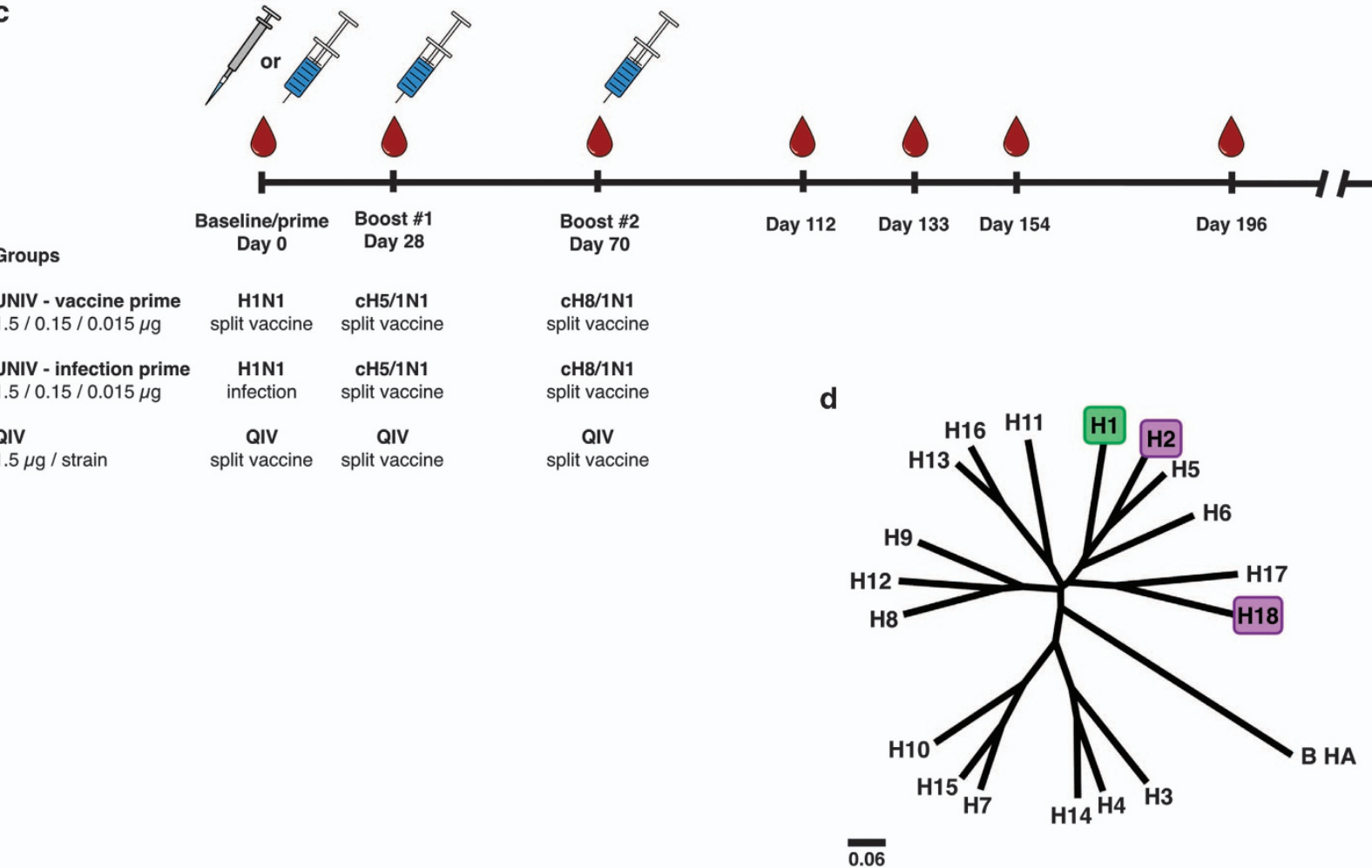

Figure 1. Chimeric haemagglutinin-based universal influenza virus vaccine concept, experimental design and phylogenetic distances of antigens. (a) Humans are repeatedly exposed to circulating H1N1 influenza viruses by infection and vaccination. This repeated exposure mainly induces antibodies against the membrane-distal, immunodominant HA head domain. (b) By combining exotic HA head domains (pictured in blue and red) with the conserved $\mathrm{H} 1$ stalk in the vaccine constructs, the immune response can be (re)directed towards conserved, immuno-subdominant epitopes in the HA stalk. (c) The mice were primed with either an $\mathrm{H} 1 \mathrm{~N} 1 \mathrm{pdm} 09$ virus vaccination or a sublethal $\mathrm{H} 1 \mathrm{~N} 1$ experimental infection on day 0 . This prime was followed by sequential $\mathrm{cH} 5 / 1 \mathrm{~N} 1$ split virus vaccination on day 28 and $\mathrm{cH} 8 / 1 \mathrm{~N} 1$ split virus vaccination on day 70 . The split vaccines were administered in 10-fold dilutions (1.5 to $0.015 \mu \mathrm{g} \mathrm{HA}$ ), either with or without AS03 adjuvant. In addition, groups of mice were vaccinated with $1.5 \mu \mathrm{g} \mathrm{HA} /$ strain of either unadjuvanted or AS03 adjuvanted QIV on days 0, 28 and day 70 . Mice vaccinated with PBS on days 0, 28 and 70, as well as mice that received a sublethal H1N1 experimental infection prime only were included as controls. The animals were followed for 296 days and bled on days 0, 28, 70, 112, 133, 154, 196 and 296 to assess antibody titres. Ten mice per group were euthanized on day 196 to test their antibodies in a serum transfer challenge experiment. (d) The mice were immunized with a vaccine containing the HA stalk domain of $\mathrm{H} 1$ (highlighted in green). To test the cross-reactive potential of these antibodies, mouse serum samples were also tested by ELISA against a closely related $\mathrm{H} 2$ protein as well as a distantly related $\mathrm{H} 18$ protein (both highlighted in purple).

\section{RESULTS}

Vaccination with cHA-based split vaccines induces stalk-reactive antibodies after inactivated $\mathrm{H} 1 \mathrm{~N} 1$ vaccination prime

To test the ability of cHA-based vaccines to induce stalk-reactive antibodies, mice were primed with a monovalent pandemic H1N1 vaccine $(\mathrm{H} 1 \mathrm{~N} 1 \mathrm{pdm} 09)$, boosted on day 28 with a $\mathrm{cH} 5 / 1 \mathrm{~N} 1$ vaccine and then again on day 70 with a $\mathrm{cH} 8 / 1 \mathrm{~N} 1$ vaccine. The prime was given to induce a low level of HA stalk-reactive antibodies that could then be boosted with the chimeric vaccines. The vaccines were given at three different doses $(0.015 \mu \mathrm{g} \mathrm{HA}$, UNIV cHA 0.015; $0.15 \mu \mathrm{g} \mathrm{HA}$, UNIV CHA 0.15; and $1.5 \mu \mathrm{g} \mathrm{HA}$, UNIV cHA 1.5) with or without $\mathrm{ASO} 3$ adjuvant. Control groups included mice that received adjuvanted or non-adjuvanted QIV (at $1.5 \mu \mathrm{g} \mathrm{HA} /$ strain) or phosphate-buffered saline (PBS). The mice were bled on the days of vaccination $(0,28,70)$ as well as on day 112, 133, 154, 195 and 296 (Figure 1c) and the serum was analysed for reactivity to the $\mathrm{HA}$ stalk (using a $\mathrm{cH} 6 / 1 \mathrm{HA}$ as antigen). In addition, we assessed reactivity to the heterosubtypic group $1 \mathrm{HAs} \mathrm{H} 2$ and $\mathrm{H} 18$.

Anti-H1 stalk titres in the adjuvanted groups rose to $1: 8,100$ on D28 after adjuvanted H1N1 vaccine priming except for the UNIV cHA 0.015 group that only reached a titre of 1:2,700 (Figure 2a). As expected, the ASO3 adjuvanted QIV group also attained a titre of $1: 8,100$ as the vaccine also has a H1N1pdm09 component. Titres of two UNIV CHA groups ( 1.5 and $0.15 \mu \mathrm{g}$ ) increased to $1: 218,700$ by day 70 after adjuvanted $\mathrm{CH} 5 / 1 \mathrm{~N} 1$ vaccination on day 28 
H1 stalk-antibody titers

a

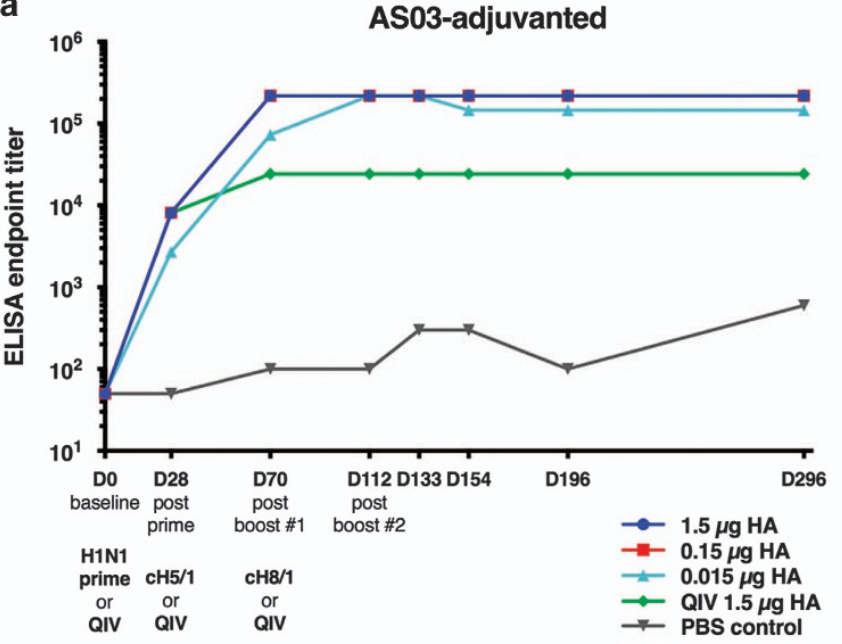

b

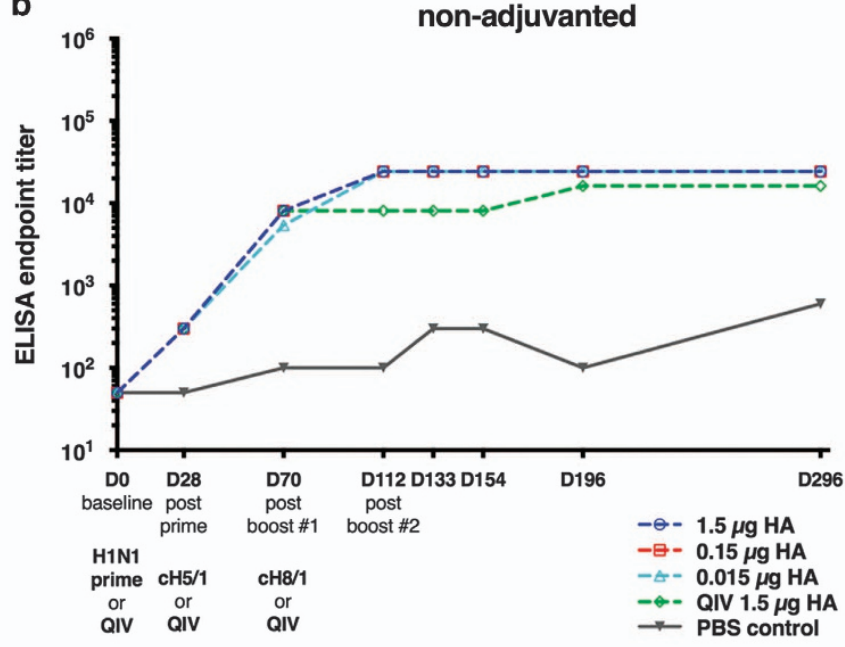

H2 cross-reactive antibody titers
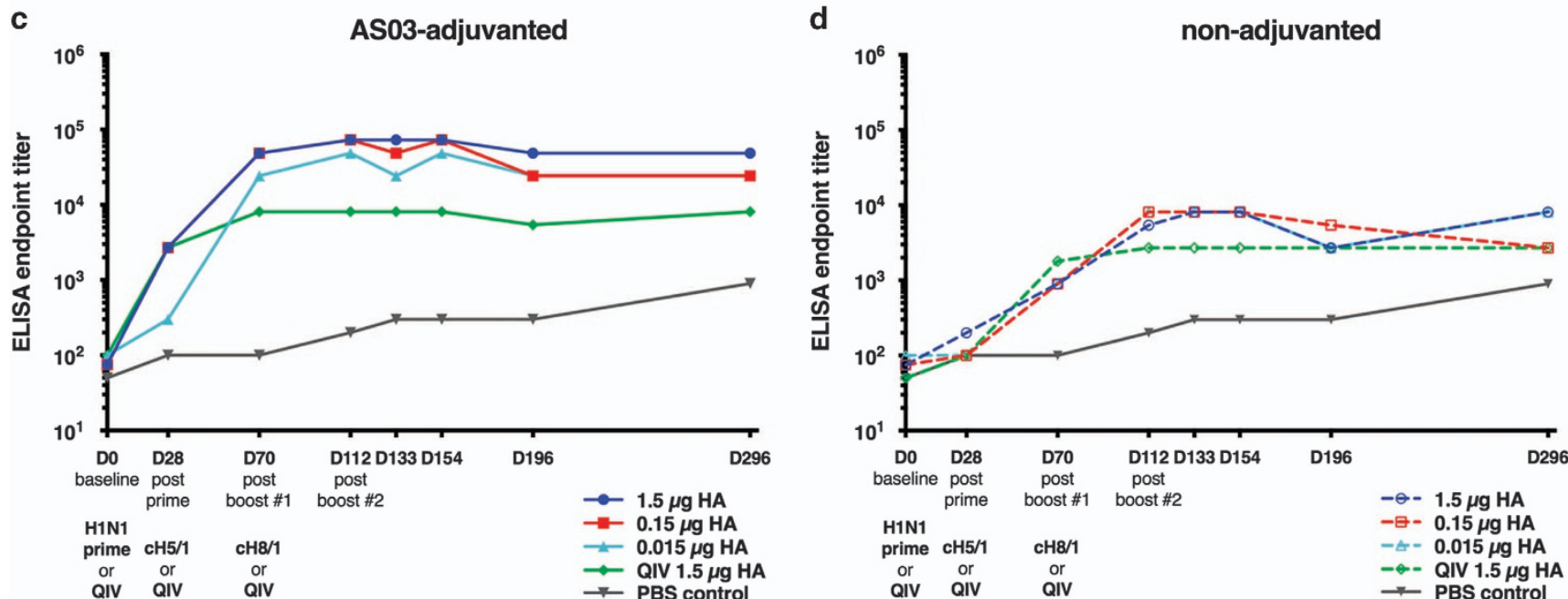

Figure 2. ELISA antibody titres after priming by $\mathrm{H} 1 \mathrm{~N} 1 \mathrm{pdm} 09$ vaccine. Antibody titres in pooled sera over time are shown against the $\mathrm{H} 1$ stalk (a and $\mathbf{b}$ ), $\mathrm{H} 2$ (c and $\mathbf{d}$ ) and $\mathrm{H} 18$ (e and $\mathbf{f})$. Antibody titres of $\mathrm{H} 1 \mathrm{~N} 1 \mathrm{pdm} 09$ vaccine-primed mice that received adjuvanted UNIV cHA vaccine are consistently higher than titres of mice in the adjuvanted QIV group. AS03 boosted antibody titres against all tested antigens. PBS-vaccinated mice are shown as negative control. (g) To assess statistical significance of the differences between UNIV cHA and QIV vaccinated groups, individual sera of the adjuvanted intermediate dose $(0.15 \mu \mathrm{g} \mathrm{HA})$ UNIV cHA group were compared with sera of the adjuvanted QIV (1.5 $\mu \mathrm{g}$ HA/ strain) group. On day 112 , the titres against the $\mathrm{H} 1$ stalk, $\mathrm{H} 2$ and $\mathrm{H} 18$ proteins were significantly higher in the UNIV cHA group (***** $<<0.0001$ ) than in the QIV group. (h) On day 296, the titres were still significantly higher in the UNIV cHA group against the H1 stalk, H2 and H18 $\left({ }^{* * *} P<0.0001,{ }^{* * *} P=0.0004,{ }^{*} P=0.0161\right.$, respectively). The asterisks refer to the significant zeros after the decimal point of the $p$-value. ${ }^{\mathrm{ns}} \mathrm{P}>0.05 ;{ }^{*} P \leq 0.05 ;{ }^{* *} P \leq 0.01 ;{ }^{* *} P \leq 0.001 ;{ }^{* * *} P \leq 0.0001$.

(Figure 2a) and remained at that level for the next 226 days, unchanged by the administration of adjuvanted $\mathrm{cH} 8 / 1 \mathrm{~N} 1$ vaccine. In contrast, anti-H1 stalk titres in the low-dose UNIV group $(0.015 \mu \mathrm{g})$ increased only to $1: 72,900$ by day 70 after adjuvanted $\mathrm{cH} 5 / 1 \mathrm{~N} 1$ vaccine and then to $1: 218,700$ by day 112 after adjuvanted $\mathrm{cH} 8 / 1 \mathrm{~N} 1$ vaccine administered on D70; titres fell 2-fold by day 154 and persisted at that level until day 296 (Figure 2a). The adjuvanted QIV group's titre increased slightly by D70 to $1: 24,300$ after receiving a second dose of adjuvanted QIV on D28 and remained at this level (9-fold lower than the peak titres/plateaus of the UNIV groups) for the duration of the experiment despite administration of a third adjuvanted QIV dose.

Next, we tested whether the UNIV candidate induced antibodies against the heterosubtypic $\mathrm{H} 2$ and $\mathrm{H} 18$ HAs. These two HAs are both group 1 HAs but their phylogenetic distance to $\mathrm{H} 1$ is different-with $\mathrm{H} 2$ being close to $\mathrm{H} 1$ and $\mathrm{H} 18$ being distantly related (Figure 1d). ${ }^{23}$ Importantly, H18 lacks a functional sialic acid binding site, which distinguishes it from regular HAs. ${ }^{24}$ Among all groups, the adjuvanted $\mathrm{H} 1 \mathrm{~N} 1$ vaccine priming dose was less effective in eliciting an anti-H2 response and even less effective in eliciting an anti-H18 response. Accordingly, anti-H2 titres were slightly lower than the anti-H1 stalk titres at subsequent time points. The UNIV 1.5, UNIV 0.15 and UNIV 0.015 groups reached peak titres of 1:72,900, 1:72,900 and 1:42,089 that decreased on day 196 (1.7-fold, 3-fold and 1.7-fold, respectively) and were then maintained at high levels until day 296 (Figure 2c). The peak anti-H2 titre of the UNIV 1.5 group was 3 -fold lower than the anti-H1 stalk titre. Vaccination with three doses of adjuvanted QIV at $1.5 \mu \mathrm{g} \mathrm{HA} /$ strain induced even lower anti-H2 titres $(1: 8,100)$. The UNIV candidate also elicited anti-H18 reactivity, although it 
H18 cross-reactive antibody titers

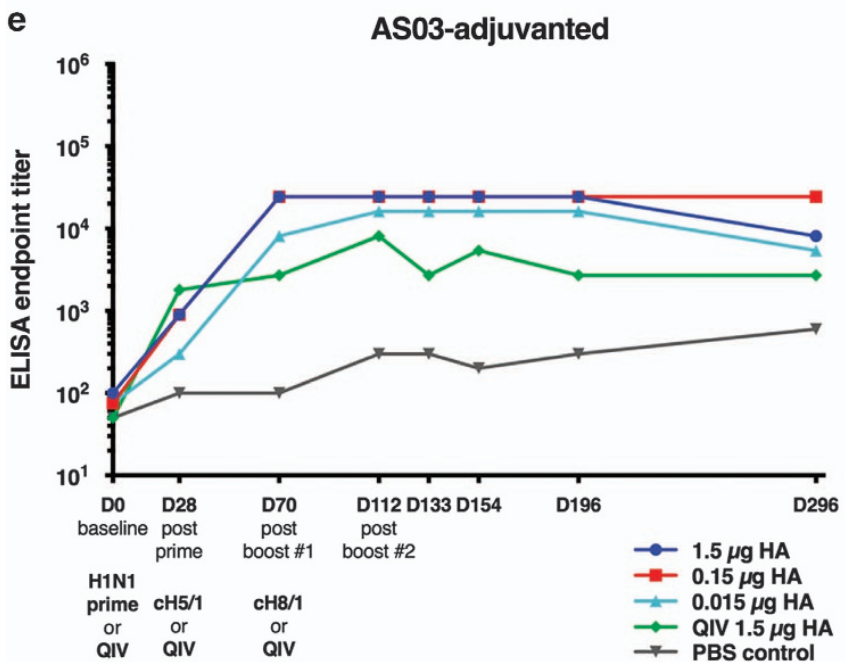

f

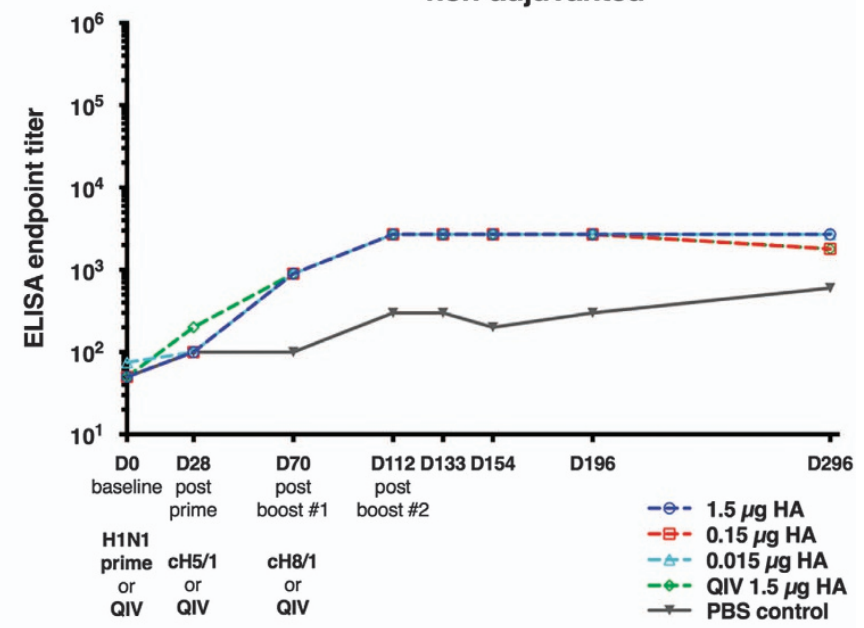

Individual antibody titers

g

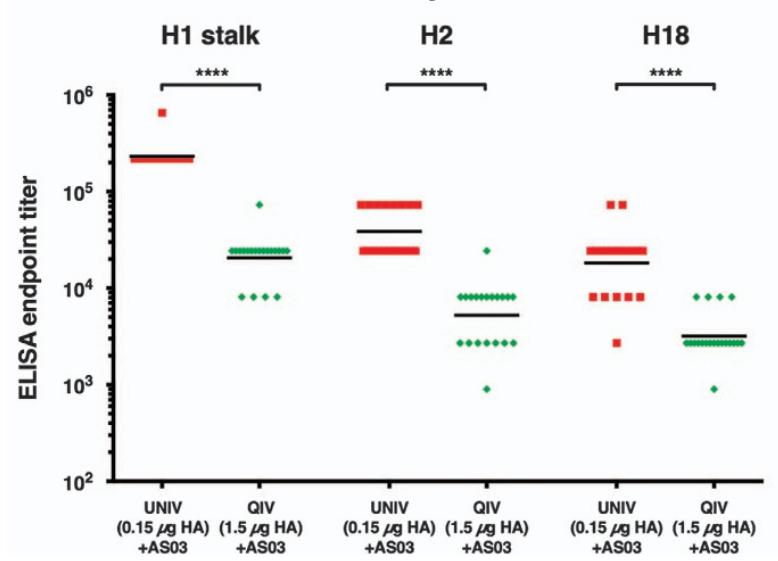

h

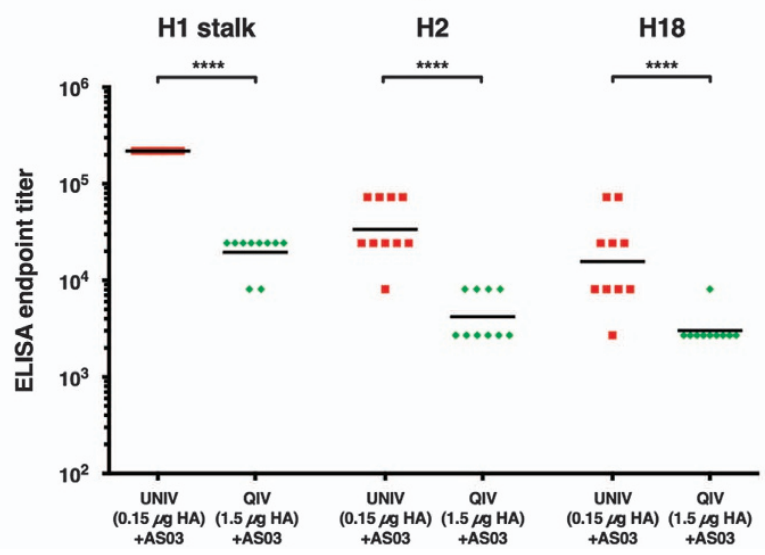

Figure 2. (Continued)

was reduced relative to anti-H2 with titres of 1:24,300, 1:24,300 and $1: 14,030$ (for the 1.5, 0.15 and 0.015 HA doses, respectively; Figure 2e). Titres in the UNIV 1.5 group were maintained until the termination of the experiment, titres in the two lower doses were slightly falling off after day 196 (Figure 2e). Peak anti-H18 titres in the UNIV 1.5 group were 9-fold lower than the peak anti-H1 stalk titres. Again, vaccination with three doses of adjuvanted QIV (1.5 $\mu \mathrm{g} \mathrm{HA} /$ strain) induced a lower anti-H18 titre of 1:8,100.

Finally, to ascertain that the difference between the groups was not driven by a small number of highly responding animals, reactivity of individual mice from the adjuvanted QIV $1.5 \mu \mathrm{g} \mathrm{HA} /$ strain group and the adjuvanted UNIV cHA $0.15 \mu \mathrm{g}$ group at 196 and 296 days post vaccination was measured. At both the time points, we found very uniform responses (Figures $2 \mathrm{~g}$ and $\mathrm{h}$ ). Individual titres were similar to the titres measured in the pools. At both the time points, reactivity in the UNIV cHA 0.15 group was statistically significantly higher than in the adjuvanted QIV 1.5 group for anti-H1 stalk, anti-H2 and anti-H18 antibody titres (Figures $2 \mathrm{~g}$ and $\mathrm{h}$ ).

In addition to the AS03-adjuvanted UNIV candidates and QIV control, we also tested non-adjuvanted split vaccines which are known to be poorly immunogenic in naive mice. ${ }^{25-27}$ Reactivity measured in mice that received non-adjuvanted vaccine showed a similar pattern to the reactivity measured in the corresponding adjuvanted groups, but in general, responses were approximately 9-fold lower (Figures 2b, $d$ and f).

cHA vaccines boost infection-induced pre-existing stalk-reactive antibodies

The majority of the global population is first exposed to influenza virus antigens by natural infection. It is known that natural infection with influenza viruses induces stalk-reactive antibodies. $^{28-30}$ Here we wanted to investigate how well cHAbased split vaccines would boost stalk-reactive antibodies in animals primed by experimental influenza virus infection, which is a model for natural infection in humans. The mice were primed by infection with $\mathrm{H} 1 \mathrm{~N} 1 \mathrm{pdm} 09$ virus at a sublethal dose and then sequentially vaccinated with the UNIV candidates ( $\mathrm{cH} 5 / 1 \mathrm{~N} 1$ and $\mathrm{cH} 8 / 1 \mathrm{~N} 1$ at different doses). An infection-only group and a PBS group were the controls. Infection with $\mathrm{H} 1 \mathrm{~N} 1 \mathrm{pdm} 09$ induced an anti-H1 stalk titre of $1: 8,100$ and the titre remained at this level with minor fluctuation until the end of the experiment at day 296 (Figure 3a). Vaccination with all three doses of UNIV boosted anti$\mathrm{H} 1$ stalk titres to a peak/plateau of 1:218,700, a titre similar to the titre observed in adjuvanted $\mathrm{H} 1 \mathrm{~N} 1$ vaccination-primed mice 
H1 stalk-antibody titers

a

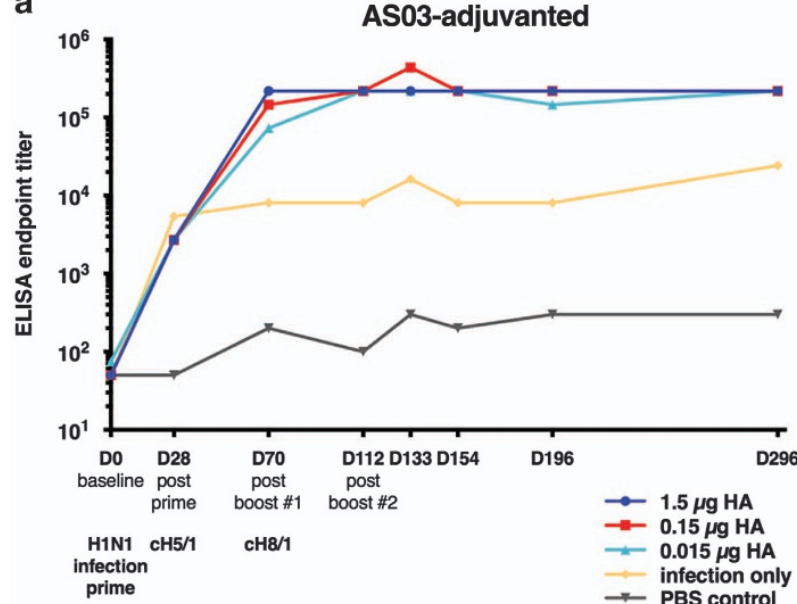

b

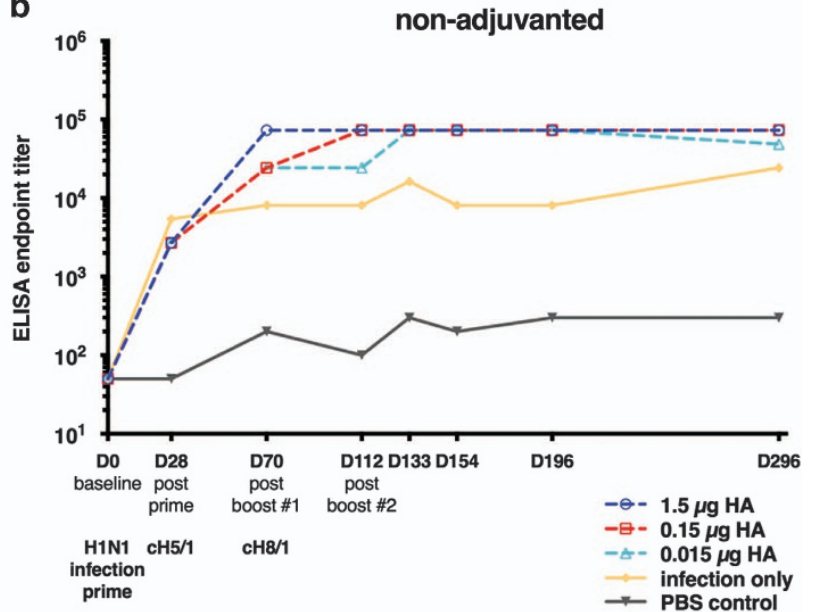

\section{H2 cross-reactive antibody titers}

C

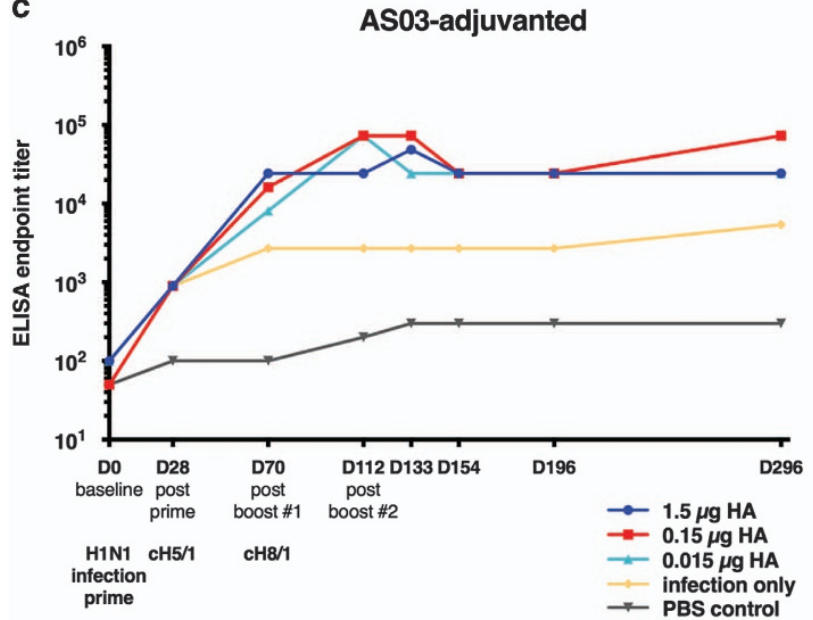

d

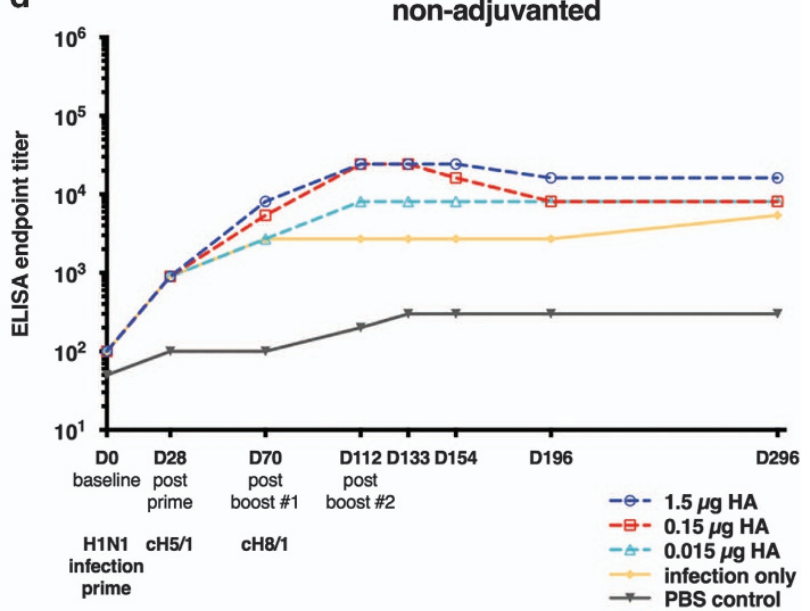

H18 cross-reactive antibody titers

e

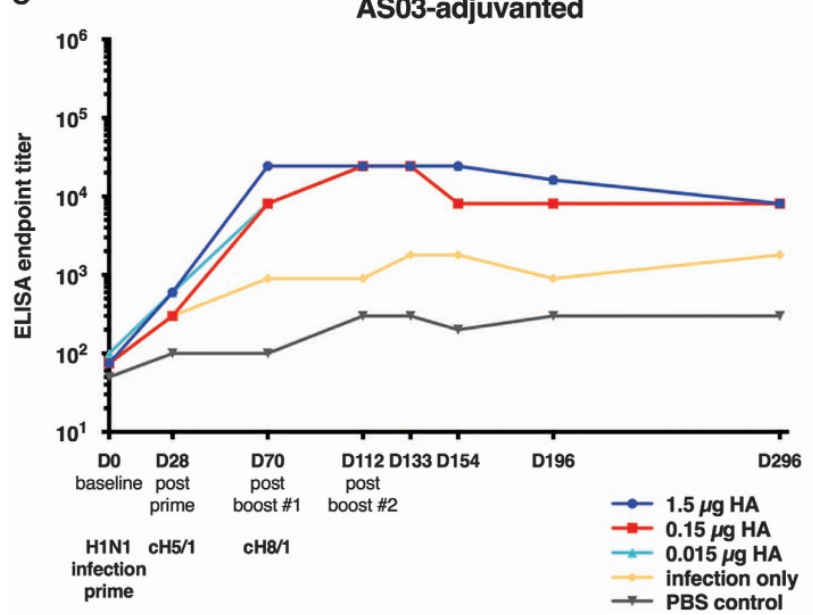

f

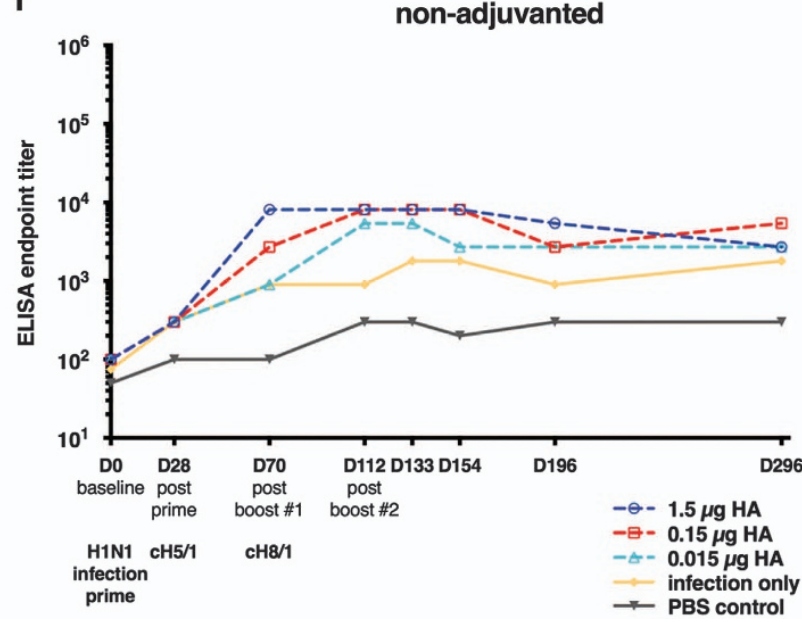

Figure 3. ELISA antibody titres after priming by $\mathrm{H} 1 \mathrm{~N} 1 \mathrm{pdm} 09$ infection. Antibody titres over time are shown against the $\mathrm{H} 1 \mathrm{stalk}(\mathbf{a}$ and $\mathbf{b})$, $\mathrm{H} 2$ (c and d) and $\mathrm{H} 18$ (e and f) after mice were primed via sublethal H1N1pdm09 infection. The mice that received an infection prime only, as well as PBS-vaccinated mice were added as controls. Antibody titres after unadjuvanted vaccination were generally lower-but higher than in the vaccine prime shown in Figure 2-and a more pronounced dose response effect was observed. 
$\mathrm{N} 1$ antibody titers (vaccination prime)
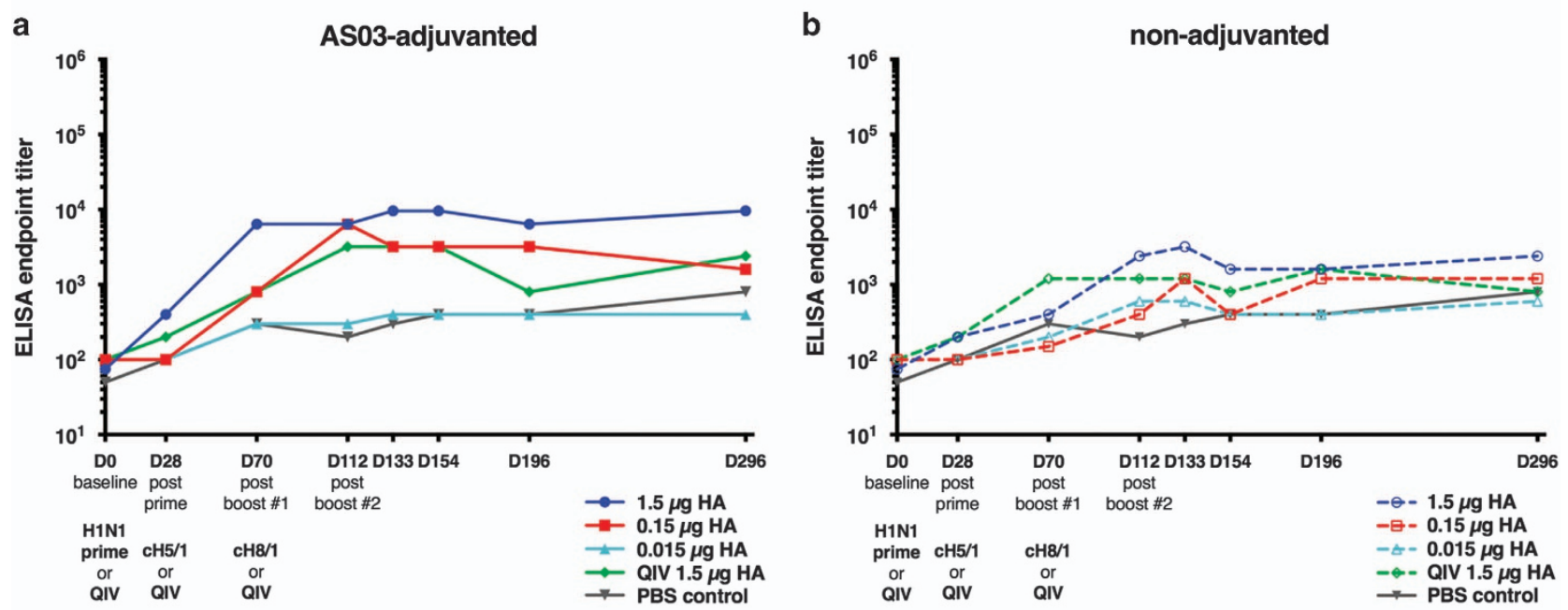

N1 antibody titers (infection prime)
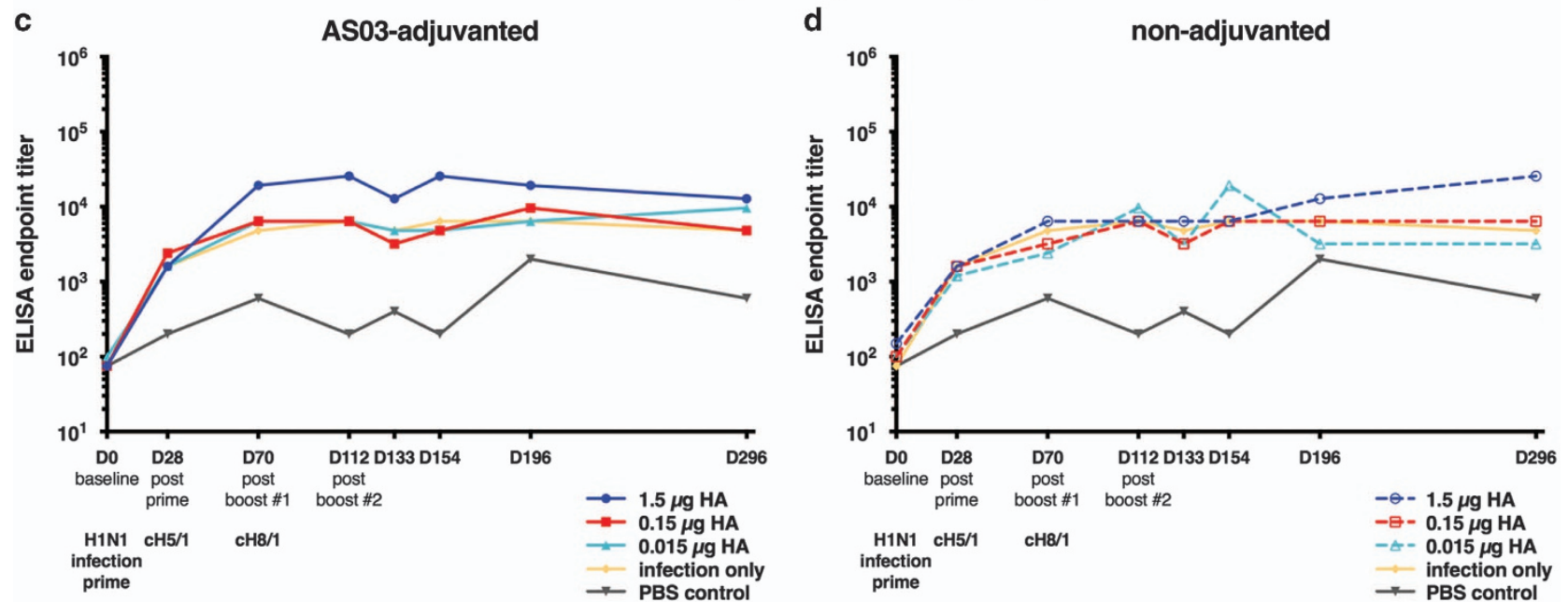

Figure 4. ELISA antibody titres against H1N1pdm09 neuraminidase. Antibody titres over time are shown against the H1N1 neuraminidase after mice were primed with either H1N1pdm09 vaccine (a and b) or sublethal H1N1pdm09 infection (c and $\mathbf{d}$ ). Antibodies against the neuraminidase were generally low and a clear dose response effect was observed for the UNIV cHA groups. Only the highest dose UNIV cHA vaccine induced consistently high NA antibody titres.

(Figure 3a and Figure 2a). Again, the second UNIV cHA vaccination on day 70 appeared to have minimal effect (Figure 3a). We also assessed reactivity to $\mathrm{H} 2$ and $\mathrm{H} 18$ in these groups. Experimental infection with $\mathrm{H} 1 \mathrm{~N} 1 \mathrm{pdm} 09$ virus induced low $(1: 2,700)$ anti-H2 titres that could be boosted by vaccination with cHAs (Figure 3c). All the three doses had a similar effect on reactivity with peak antiH2 titres of 1:72,900 on day 112 (1:24,000 for UNIV CHA 1.5; Figure $3 \mathrm{c}$ ). However, in this case, a boost caused by the second $\mathrm{cHA}$ vaccination was observed. An $\mathrm{H} 1 \mathrm{~N} 1 \mathrm{pdm} 09$ infection primed low-level anti $\mathrm{H} 18$ titres (1:900; Figure 3e). Vaccination with UNIV CHA 1.5, 0.15 and 0.015 boosted anti-H18 titres to a peak of $1: 24,300$ on day 112 . Although the second $\mathrm{cHA}$ vaccination with UNIV CHA 1.5 on day 70 appeared to have no effect, anti-H18 titres increased after the second vaccination with UNIV CHA 0.15 and 0.015 .

The experiment was also performed with non-adjuvanted vaccines. As described above, the peak/plateau titres were lower when non-adjuvanted vaccines were used and a more apparent dose response was observed for $\mathrm{H} 2$ and $\mathrm{H} 18$ cross-reactive titres (Figure 3b, $d$ and f). However, the difference in peak titres between adjuvanted and non-adjuvanted UNIV cHA groups was smaller (approximately 3-fold) when mice were primed by experimental H1N1pdm09 infection compared with mice primed with H1N1pdm09 vaccine (approximately 9-fold difference, as described above).

cHA vaccines boost anti-neuraminidase antibodies

Induction of anti-NA antibodies is usually not assessed after vaccination with seasonal influenza virus vaccines and no correlation between NA-specific antibody titres and protection has been formally established yet. However, there are many reports that indicate that antibodies to the NA can contribute substantially to protection. ${ }^{17,31-37}$ To characterize the anti-NA response to the UNIV candidate, we performed quantitative enzyme-linked immunosorbent assays (ELISAs) using recombinant tetrameric N1 (H1N1pdm09) as the antigen. Titres in the adjuvanted UNIV CHA 1.5 group increased after the H1N1pdm09 prime and after the $\mathrm{CH} 8 / 1$ boost and reached a plateau at 1:8,100 that was maintained until the end of the experiment (Figure 4a). The UNIV cHA 0.15 and 0.015 candidates were less immunogenic, with UNIV CHA 0.15 peaking at 1:6,400 at day 112 and slowly 


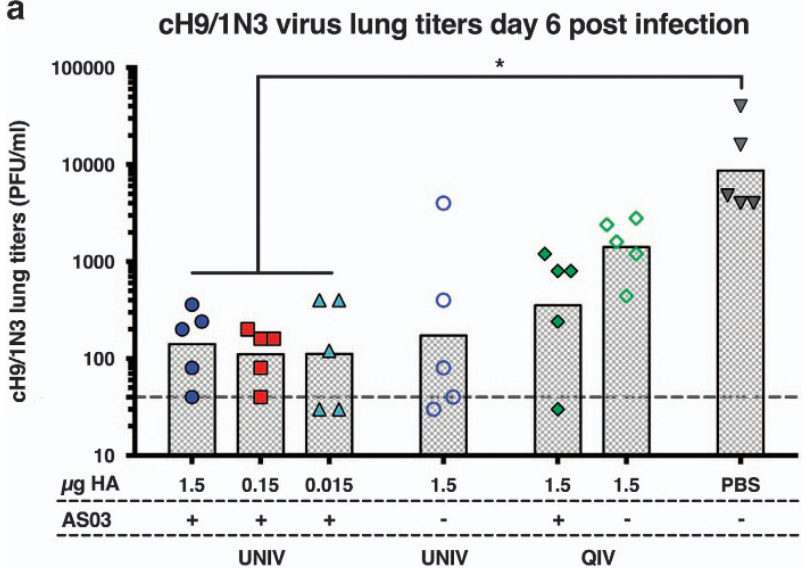

b

3-fold lower peak titres (Figure 4b). Interestingly, priming by experimental infection induced moderate anti-NA titres, which could be boosted 16-fold to 1:25,600 by the highest adjuvanted UNIV $(1.5 \mu \mathrm{g})$ regimen (Figure $4 \mathrm{c}$ ). All other vaccines failed to boost anti-NA titres above the level of the experimental infection prime (Figures $4 c$ and d). We also tested reactivity to an N3 NA antigen. Titres were low and no statistical difference between the different groups was observed (data not shown).

Transfer of sera containing anti-H1 stalk antibodies reduces virus replication in recipient mice

Next, we assessed whether the anti-stalk antibodies induced by sequential vaccination with cHAs have biological activity in vivo in a serum transfer/challenge approach. ${ }^{38}$ Ten mice from the three AS03-adjuvanted UNIV CHA groups, the non-adjuvanted UNIV cHA 1.5 group, the adjuvanted and the non-adjuvanted QIV groups, and the PBS control group were terminally bled on day 196. Sera were pooled within groups and then transferred into naive mice. Two hours post transfer, these mice were challenged with a $\mathrm{cH} 9 / 1 \mathrm{~N} 3$ virus that expresses an $\mathrm{H} 9$ head domain in combination with an $\mathrm{H} 1$ stalk domain and a N3 neuraminidase. ${ }^{28,39,40}$ As sera from sequentially vaccinated mice will only react to the $\mathrm{H} 1$ stalk domain but not to the $\mathrm{H} 9$ head $^{39}$ and the N3 NA, this virus allows the assessment of protection conferred by anti-stalk antibodies only. ${ }^{39}$ On day 6 post challenge, the mice were killed, lungs were harvested and viral titres were measured in a plaque assay. The mice that were administered serum from the PBS control group had lung virus titres in the range of $10^{4}$ plaque-forming unit (PFU)/ $\mathrm{ml}$ (geometric mean titre of $8,676 \mathrm{PFU} / \mathrm{ml}$, Figure $5 \mathrm{a}$ ). The mice administered serum from recipients of non-adjuvanted QIV and adjuvanted QIV showed reduced geometric mean virus lung titres of $1,415 \mathrm{PFU} / \mathrm{ml}$ and $354 \mathrm{PFU} / \mathrm{ml}$, respectively. The animals that were administered serum from recipients of non-adjuvanted $\mathrm{cHA}$ vaccine (UNIV CHA 1.5) showed even lower geometric lung titres of $173 \mathrm{PFU} / \mathrm{ml}$ but the individual titres were relatively nonhomogeneous. Geometric mean titres for all animals that were administered serum from recipients of adjuvanted UNIV CHA groups were low and homogeneous (141, 110, 111 PFU/ml). Importantly, the reduction of viral lung titres compared with the PBS control group was only significant in the AS03-adjuvanted UNIV cHA groups. Furthermore, the serum anti-stalk titre measured by ELISA correlated inversely with lung virus titres (Spearman $r=-0.9543, P=0.0048$, Figure $5 b$ ).

challenge. To assess in vivo protective activity of anti-stalk antibodies, sera harvested from 10 mice on day 196 were transferred into naive mice, which were then challenged with the $\mathrm{cH} 9 / 1 \mathrm{~N} 3$ virus. (a) Viral lung titres were significantly lower only in mice that received serum from the AS03-adjuvanted UNIV CHA groups as compared with titres in mice that received serum from the PBS control group (UNIV cHA $1.5 \mu \mathrm{g} \mathrm{HA} P=0.0416$, UNIV cHA $0.15 \mu \mathrm{g} \mathrm{HA}$ $P=0.0149$, UNIV cHA $0.015 \mu \mathrm{g}$ HA $P=0.0176$ ). Transfer of serum from animals vaccinated with QIV with and without ASO3 adjuvant, as well as UNIV $\mathrm{CHA} 1.5 \mu \mathrm{g} \mathrm{HA}$ without adjuvant resulted in moderate reduction in viral titres. (b) ELISA antibody titres against the $\mathrm{H} 1$ stalk are negatively correlated with viral lung titres (Spearman $r=-0.9543, P=0.0048$ ). This further supports the hypothesis that the protection from viral infection in the experiment was conferred by stalk antibodies. The asterisks refer to the significant zeros after the decimal point of the $p$-value. Symbol meaning ${ }^{n s} p>0.05$; ${ }^{*} P \leq 0.05 ;{ }^{*} P \leq 0.01 ;{ }^{* * *} P \leq 0.001 ;{ }^{* * *} P \leq 0.0001$.

declining over time and UNIV CHA 0.015 showing no reactivity above that of the PBS control demonstrating a dose response for the N1 antigen. Adjuvanted QIV administered thrice was similarly immunogenic to UNIV 0.15 , whereas the UNIV 1.5 regimen was approximately 3-fold more immunogenic than the adjuvanted QIV (also $1.5 \mu \mathrm{g}$ of purified $\mathrm{HA}$; Figure 4a). Similar results were obtained with non-adjuvanted vaccines albeit at approximately

\section{DISCUSSION}

Chimeric HA-based universal influenza vaccines aim at inducing high levels of broadly protective antibodies by re-directing the immune response to the conserved stalk domain and by breaking the immunodominance of the head domain., ${ }^{8,41}$ Although the overall concept has been proven in animal models using experimental vaccine platforms like DNA vaccination and virusvectored vaccines, ${ }^{19,20,41-44}$ we wanted to explore whether split virus vaccines produced using an industrial pilot scale production process would support this approach as well. This question is important to investigate as a positive result would support evaluation of the cHA vaccines in human subjects. Here we demonstrate that $\mathrm{cHA}$-based split vaccines induce stalk-reactive antibodies in primed mice. As hypothesized, sequential vaccination with $\mathrm{CHA}$ induced a higher lgG antibody titre than vaccination with three doses of QIV. The adjuvant had an important role in inducing high anti-stalk IgG antibody titres and the titres achieved with non-adjuvanted split vaccine were significantly lower. $^{45}$ However, it is important to mention that non-adjuvanted split vaccines have previously been found to be poorly immunogenic in murine and ferret models compared with whole virus, most likely due to the absence of significant amounts of pathogen- 
associated molecular patterns. ${ }^{25-27,46}$ Importantly, although nonadjuvanted cHA-based vaccines did not induce very high titres in vaccine-primed mice, they efficiently boosted stalk lgG antibodies in animals primed by experimental infection.

Furthermore, we noticed that anti-stalk antibody levels reached a titre of 1:218,700 and it could not be boosted any higher. Mice typically have relatively low total IgG serum concentrations of $1-2 \mathrm{mg} / \mathrm{ml}$ (as compared with humans who have $13 \mathrm{mg} / \mathrm{ml}$ on average). ${ }^{47}$ Under the assumption that all present IgG was stalkreactive (which is not the case, only a proportion of the serum IgG will react with the stalk domain), a measured titre of 1:218,700 would translate into a minimum binding concentration of 4.6$9.1 \mathrm{ng} / \mathrm{ml}$ for stalk-reactive antibodies. It has been shown that human stalk-reactive antibodies have similar minimum binding concentrations, which means that the observed plateau might be a consequence of the lower lgG serum concentrations in the mouse model. ${ }^{48}$ In fact, serum from mice that received the lowest tested $\mathrm{cHA}$ dose $(0.015 \mu \mathrm{g} \mathrm{HA})$ did not reach this plateau after priming and one dose of $\mathrm{cHA}$ vaccine; however, the second $\mathrm{cHA}$ vaccine dose did boost antibody titres.

Anti-stalk antibodies have been shown to cross-react and crossneutralize different HA subtypes, mostly within the same HA group. ${ }^{47,49-51}$ However, it is important to keep in mind that not all induced stalk-reactive antibodies will cross-react and that some antibodies will have more narrow reactivity patterns than others. In our study, reactivity was highest towards $\mathrm{H} 1$, followed by $\mathrm{H} 2$ (approximately 3-fold lower) and $\mathrm{H} 18$ (approximately 9-fold lower). Interestingly this also reflects the phylogenetic distance between these three HAs (Figure 1d). This lower reactivity to HAs that are more distantly related to the HA stalk used for vaccination is expected and has been observed previously but the level of antibody reached might still afford full protection against heterosubtypic challenge. ${ }^{9,10}$ However, cross-reactivity between group A1 and group A2 HA stalk domains is low, which makes it necessary to also develop a group A2 universal vaccine component $^{8-10,47}$ (in addition to a conserved $B$ virus constituent) as part of a multivalent universal influenza virus vaccine.

In addition to anti-stalk antibodies, the cHA-based vaccine also induced robust anti-NA titres when given with the AS03 adjuvant at the highest dose. Interestingly, the adjuvanted high-dose cHA vaccine was also the only treatment in our study that boosted titres of anti-NA antibodies induced by experimental infection. This is important as the majority of the global population is first exposed to influenza virus antigens via natural infection. However, this is only relevant for viruses expressing N1 and N2 NAs as no pre-existing immunity induced by natural infection exists in the population against N3-N9 NAs.

Finally, our results demonstrate that anti-stalk titres can be maintained at high levels over a long period of time, at least in the mouse model. This is highly important since a universal influenza vaccine that induces only short-term immunity would be of limited use. The data reported here support the further development of cHA-based broadly protective influenza virus constructs and pave the way for future clinical evaluation of these vaccine candidates.

\section{MATERIALS AND METHODS}

Vaccines, viruses and adjuvants

The investigational monovalent $\mathrm{CH} 5 / 1 \mathrm{~N} 1$ and $\mathrm{CH} 8 / 1 \mathrm{~N} 1$ egg-derived, inactivated, split virion vaccines were produced from $\mathrm{CH} 5 / 1_{\text {Calog }} \mathrm{N} 1$ Calo9 and $\mathrm{CH} 8 / 1_{\text {Calog }} \mathrm{N} 1_{\text {Calog }}$ reverse genetics viruses as described previously. ${ }^{22,52}$ The $\mathrm{H} 5$ head domain of $\mathrm{CH} 5 / 1_{\text {Calog }} \mathrm{N} 11_{\text {Calog }}$ virus was derived from the $\mathrm{HA}$ of A/Vietnam/1203/04 (H5N1), the head domain of the $\mathrm{CH} 8 / 1_{\text {Calog }} \mathrm{N} 1_{\text {Calog }}$ virus was derived from the HA of $\mathrm{A} /$ mallard/Sweden/24/02 (H8N4), the stalk domain and NA of both viruses was derived from A/California/04/09 (H1N1) and the internal genes were derived from the high-yielding vaccine donor strain A/Puerto Rico/8/34 (H1N1). The $\mathrm{CH} 5 / 1$ and $\mathrm{CH} 8 / 1$ antigens were influenza-split virions produced by GSK (Sainte-Foy, QC, Canada). The HA content of these vaccines was determined by densitometry of Coomassie blue-stained SDS-PAGE gels. The monovalent H1N1 egg-derived, inactivated, split virion vaccine was produced from A/ California/7/2009 (H1N1) NYMC X-179A reassortant virus generated using classical reassortant methodology by GSK. The HA content of this vaccine was determined by single radial immuno-diffusion assay using reagents from Center for Biologics Evaluation and Research (Food and Drug Administration, MD, USA) or National Institute for Biological Standards and Control (Hertfordshire, UK). The seasonal quadrivalent inactivated, split virion vaccine was the 2011 Northern Hemisphere vaccine that was produced from A/California/7/2009 (H1N1) NYMC X-179A and A/Victoria/ 210/2009 (H3N2) NYMC X-187 reassortant viruses generated using classical reassortant methodology as well as B/Brisbane/60/2008 (B/Victoria lineage) and $\mathrm{B} /$ Florida/4/2006 (B/Yamagata lineage) wild-type viruses. The HA content of the seasonal quadrivalent vaccine was determined by single radial immuno-diffusion assay using reagents from Center for Biologics Evaluation and Research or National Institute for Biological Standards and Control. All vaccines used in this study were manufactured in embryonated eggs by GSK Vaccines. The A/California/7/2009 (H1N1) wild-type virus (kindly supplied by Xiyan Xu, Influenza Division, Centers for Disease Control and Prevention, Atlanta, GA, USA) was propagated on Madin-Darby Canine Kidney cells before priming the mice. AS03 was manufactured by GSK Vaccines. ${ }^{53,54} \mathrm{ASO}_{\mathrm{B}}$ is defined as an Adjuvant System containing atocopherol and squalene in an oil-in-water emulsion $(5.93 \mathrm{mg}$ tocopherol/ dose). The AS03 used for the studies described herein is equivalent to 1/10th of the adult human dose of $\mathrm{ASO}_{\mathrm{B}}$, and hereafter is referred to as AS03. The split virion vaccines were ad-mixed with the AS03 by gentle inversion preceding each immunization.

\section{Immunogenicity study design and treatment schedule}

All mouse procedures were approved in advance by the Institutional Animal Care Committee at the Institut Armand Frappier (Laval, QC, Canada) according to the guidelines of the Canadian Council on Animal Care. Six- to eight-week-old female BALB/C mice (Charles River, Saint-Constant, QC, Canada) were randomly assigned to a treatment group ( $n=20$ mice per group). The mice were first primed intranasally with live $A /$ California/ $7 / 2009$ (H1N1) wild-type virus ( $10^{6}$ tissue culture infectious dose 50 ) or intramuscularly with a 100 -fold dose range of the $\mathrm{H} 1 \mathrm{~N} 1 \mathrm{pdm} 09$ vaccine (1.5 to $0.015 \mu \mathrm{g} \mathrm{HA}) \pm$ AS03 on study day 0 . The virus and vaccine primed mice were then serially immunized intramuscularly with a 100 -fold dose range of the monovalent detergent-split $\mathrm{CH} 5 / 1$ and $\mathrm{cH} 8 / 1$ universal influenza vaccines (UNIV, 1.5 to $0.015 \mu \mathrm{g} \mathrm{HA}$ ) \pm AS03 on study days 28 and 70 . Additional mice (not primed with H1N1pdm09 virus or split vaccine previously) were serially immunized intramuscularly with the seasonal quadrivalent vaccine (QIV, $1.5 \mu \mathrm{g} \mathrm{HA} /$ strain) \pm ASO3 on study days 0,28 and 70 . The mice vaccinated with PBS on days 0,28 and 70 were included as negative controls for both the infection and intramuscular prime experiments. Furthermore, an infection prime-only control group was included as well. The mice were bled on study days 0, 28, 70, 112, 133, 154, 196 and 296 as shown in Figure $1 \mathrm{c}$, and the serum IgG antibody titres to $\mathrm{CH} 6 / 1 \mathrm{HA}$ (group 1 stalk) as well as $\mathrm{H} 2$ and $\mathrm{H} 18$ full-length $\mathrm{HA}$ were determined by ELISA.

\section{Serum transfer study design}

All the mouse procedures were approved in advance by the Institutional Animal Care and Use Committee at the Icahn School of Medicine at Mount in accordance with the Animal Act PL99-158 (as amended) and guidelines stated in the 'Guide for the Care and Use of Laboratory Animals'. Six-toeight-week-old female BALB/c mice (The Jackson Laboratory, Bar Harbor, $M E, U S A)$ were randomly assigned to a treatment group. Ten mice from each group in the immunization study were terminally bled on day 196 post prime vaccination. Serum pools were created for all groups that received the inactivated virus prime, except for the groups that received the lower doses $(0.15 \mu \mathrm{g} \mathrm{HA}$ and $0.015 \mu \mathrm{g} \mathrm{HA})$ of non-adjuvanted chimeric $\mathrm{HA}$. As a negative control, a pool of serum from PBS-vaccinated mice was included as well. Two hundred and fifty microlitres of pooled serum were transferred into five mice per group. Two hours after the serum transfer, the mice were challenged with $10^{5} \mathrm{PFUs}$ of chimeric H9/1N3 virus. This virus has the exotic head of an $\mathrm{HA}$ and neuraminidase to which the vaccinated mice are immunologically naive, but their serum will recognize the conserved $\mathrm{H} 1$ stalk domain of the virus. Therefore, only $\mathrm{H} 1$ stalkreactive antibodies can contribute to protection in this experiment. On day 6 post challenge, the mice were killed and their lungs extracted. The lungs 
were homogenized, cell debris removed by centrifugation and supernatants frozen at $-80{ }^{\circ} \mathrm{C}$ until further use. Virus titres in the lung supernatants were measured by plaque assay as previously described. ${ }^{28,39}$

\section{ELISA methodology}

The recombinant $\mathrm{CH} 6 / 1$ (head domain from $\mathrm{HA}$ of $\mathrm{H} 6 \mathrm{~N} 1$ virus $\mathrm{A} /$ mallard/ Sweden/81/02, stalk domain from $\mathrm{HA}$ of $\mathrm{H} 1 \mathrm{~N} 1$ virus $\mathrm{A} /$ Puerto Rico/8/34), $\mathrm{H} 2$ (A/mallard/Netherlands/5/99), H18 (A/flat-faced bat/Peru/033/10), N1 (A/California/04/09) and N3 (A/swine/Missouri/4296424/06) proteins that were used as ELISA substrates were produced using the baculovirus expression system in insect cells as described previously. ${ }^{55,56}$ The serum samples were pooled for ELISA analysis and tested in technical duplicates. In addition, to test statistical significance of the differences in $\mathrm{H} 1$ stalk antibody titres, individual serum samples were tested for reactivity on day 112 and day 296 post prime for the AS03-adjuvanted QIV group and the AS03-adjuvanted, second highest dose $(0.15 \mu \mathrm{g} \mathrm{HA})$ chimeric HA group. High-binding 96-well ELISA plates (Thermo Scientific, Waltham, MA, USA) were coated with $50 \mu \mathrm{l}$ of antigen diluted at a concentration of $2 \mu \mathrm{g} / \mathrm{ml}$ in coating buffer $(50 \mathrm{mM}$ sodium carbonate, $50 \mathrm{mM}$ sodium hydrogen carbonate, $\mathrm{pH}$ 9.4). The plates were incubated for $12-18 \mathrm{~h}$ at $4{ }^{\circ} \mathrm{C}$ and the coating solution was removed with three washes of PBS-T (PBS, $0.1 \%$ Tween-20, pH 7.4). The plates were blocked with $220 \mu$ l of blocking solution (PBS-T with 3\% milk powder) per well for $1 \mathrm{~h}$ at room temperature. The blocking solution was replaced with $100 \mu \mathrm{l}$ of fresh blocking solution per well. For 3 -fold dilutions, additional $40 \mu \mathrm{l}$ of blocking solution was added to the first well of each dilution series ( $90 \mu \mathrm{l}$ for 2 -fold dilutions). Ten microlitres of pre-diluted serum was added to the first well of each dilution series. Fifty microlitres were transferred for 3 -fold serial dilutions $(100 \mu l$ for 2 -fold dilutions). Two columns per plate did not contain any serum and were used as blanks. The plates were incubated for $2 \mathrm{~h}$ at room temperature and then washed three times with PBS-T. Horse radish peroxidase-labelled anti-mouse IgG (whole molecule, Sigma, St. Louis, MO, USA) was used as secondary antibody. Fifty microlitres of secondary antibody diluted at a concentration of 1:3,000 in blocking solution was added to each well and the plates were incubated for $1 \mathrm{~h}$ at room temperature. The plates were washed four times and developed with $100 \mu \mathrm{l}$ of SigmaFast OPD (Sigma) substrate per well for $10 \mathrm{~min}$. Enzymatic colour development was stopped with $50 \mu \mathrm{l}$ of $3 \mathrm{M}$ hydrochloric acid per well and the plates were read at an absorbance of $490 \mathrm{~nm}$. The results are reported as end-point titres. The end-point titre was defined as the last dilution in which the reactivity of a serum sample was still above the cutoff of the average of the blanks plus three standard deviations.

\section{Data analysis}

Data were analysed using Microsoft Excel and Graphpad Prism software. Statistical differences for ELISA titres were calculated with unpaired $t$-tests. Day 6 virus lung titres were compared with a Kruskal-Wallis test and a Dunn's multiple comparisons test. Correlation of day 6 virus lung titres and $\mathrm{H} 1$ stalk antibody titres was calculated by nonparametric Spearman correlation, and a nonlinear log-log line fit was plotted.

\section{ACKNOWLEDGEMENTS}

The authors thank Ulrike Krause (GSK Vaccines, Rixensart, Belgium) for editorial assistance and coordinating the review of the manuscript. This work was partially supported by the Biomedical Advanced Research and Development Authority (BARDA, HHSO100201500010C) and GlaxoSmithKline Biologicals SA. Partial support was provided by NIH grants U19 Al109946 (PP and FK) and P01 Al097092 (PP and FK).

\section{CONTRIBUTIONS}

R.N., D.K., A.C., A.H. and E.B. performed the experiments. R.N., B.L.I., N.L., P.P., C.P.M. and F.K. designed the experiments and analysed the data. R.N., C.P.M. and F.K. wrote the manuscript with input from B.L.I., N.L., E.B. and P.P. All the authors had access to the data and approved the manuscript before it was submitted by the corresponding author.

\section{COMPETING INTERESTS}

All the authors have declared that the following interests are relevant to the submitted work. The Icahn School of Medicine at Mount Sinai holds several patents in the area of influenza virus vaccines. $\mathrm{EB}, \mathrm{BLI}, \mathrm{NL}$ and $\mathrm{CPM}$ are, or were at the time of the studies, employees of the GSK group of companies. BLI, NL and CPM own stock in GSK. BLI, NL and CPM are listed as an inventor on patents owned by the GSK group of companies.

\section{REFERENCES}

1. Tricco, A. C. et al. Comparing influenza vaccine efficacy against mismatched and matched strains: a systematic review and meta-analysis. BMC Med. 11, 153 (2013).

2. Krammer, F. \& Palese, P. Advances in the development of influenza virus vaccines. Nat. Rev. Drug Discov. 14, 167-182 (2015).

3. Gerdil, C. The annual production cycle for influenza vaccine. Vaccine $\mathbf{2 1}$ 1776-1779 (2003).

4. Palese, P. Influenza: old and new threats. Nat. Med. 10, S82-S87 (2004).

5. Ohmit, S. E., Petrie, J. G., Cross, R. T., Johnson, E. \& Monto, A. S. Influenza hemagglutination-inhibition antibody titer as a correlate of vaccine-induced protection. J. Infect. Dis. 204, 1879-1885 (2011).

6. Heaton, N. S., Sachs, D., Chen, C. J., Hai, R. \& Palese, P. Genome-wide mutagenesis of influenza virus reveals unique plasticity of the hemagglutinin and NS1 proteins. Proc. Natl Acad. Sci. USA 110, 20248-20253 (2013).

7. Gerhard, W., Yewdell, J., Frankel, M. E. \& Webster, R. Antigenic structure of influenza virus haemagglutinin defined by hybridoma antibodies. Nature 290 713-717 (1981).

8. Krammer, F., Pica, N., Hai, R., Margine, I. \& Palese, P. Chimeric hemagglutinin influenza virus vaccine constructs elicit broadly protective stalk-specific antibodies. J. Virol. 87, 6542-6550 (2013).

9. Yassine, H. M. et al. Hemagglutinin-stem nanoparticles generate heterosubtypic influenza protection. Nat. Med. 21, 1065-1070 (2015).

10. Impagliazzo, A. et al. A stable trimeric influenza hemagglutinin stem as a broadly protective immunogen. Science 349, 1301-1306 (2015).

11. Steel, J. et al. Influenza virus vaccine based on the conserved hemagglutinin stalk domain. MBio 1, pii: e00018-10 (2010).

12. Wohlbold, T. J. et al. Vaccination with soluble headless hemagglutinin protects mice from challenge with divergent influenza viruses. Vaccine 33, 3314-3321 (2015).

13. Lambe, T. et al. Immunity against heterosubtypic influenza virus induced by adenovirus and MVA expressing nucleoprotein and matrix protein-1. Sci. Rep. 3, 1443 (2013).

14. Giles, B. M. \& Ross, T. M. Computationally optimized antigens to overcome influenza viral diversity. Expert Rev. Vaccines 11, 267-269 (2012).

15. Lu, Y., Welsh, J. P. \& Swartz, J. R. Production and stabilization of the trimeric influenza hemagglutinin stem domain for potentially broadly protective influenza vaccines. Proc. Natl Acad. Sci. USA 111, 125-130 (2014).

16. Mallajosyula, V. V. et al. Influenza hemagglutinin stem-fragment immunogen elicits broadly neutralizing antibodies and confers heterologous protection. Proc. Natl Acad. Sci. USA 111, E2514-E2523 (2014).

17. Wohlbold, T. J. et al. Vaccination with adjuvanted recombinant neuraminidase induces broad heterologous, but not heterosubtypic, cross-protection against influenza virus infection in mice. MBio 6, e02556 (2015).

18. Carter, D. M. et al. Design and characterization of a COBRA HA vaccine for H1N1 influenza viruses. J. Virol. 90, 4720-4734 (2016).

19. Nachbagauer, R. et al. Hemagglutinin stalk immunity reduces influenza virus replication and transmission in ferrets. J. Virol. 90, 3268-3273 (2015).

20. Margine, I. et al. Hemagglutinin stalk-based universal vaccine constructs protect against group 2 influenza A viruses. J. Virol. 87, 10435-10446 (2013).

21. Chen, C. J. et al. Influenza A viruses expressing intra- or intergroup chimeric hemagglutinins. J. Virol. 90, 3789-3793 (2016).

22. Hai, R. et al. Influenza viruses expressing chimeric hemagglutinins: globular head and stalk domains derived from different subtypes. J. Virol. 86, 5774-5781 (2012).

23. Krammer, F. Emerging influenza viruses and the prospect of a universal influenza virus vaccine. Biotechnol. J. 10, 690-701 (2015).

24. Tong, S. et al. New world bats harbor diverse influenza A viruses. PLoS Pathog. 9 , e1003657 (2013).

25. Barry, D. W., Staton, E. \& Mayner, R. E. Inactivated influenza vaccine efficacy: diminished antigenicity of split-product vaccines in mice. Infect. Immun. 10, 1329-1336 (1974).

26. Geeraedts, F. et al. Whole inactivated virus influenza vaccine is superior to subunit vaccine in inducing immune responses and secretion of proinflammatory cytokines by DCs. Influenza Other Respir. Viruses 2, 41-51 (2008).

27. Stoel, M. et al. Innate responses induced by whole inactivated virus or subunit influenza vaccines in cultured dendritic cells correlate with immune responses in vivo. PLoS One 10, e0125228 (2015).

28. Nachbagauer, R. et al. Age dependence and isotype specificity of influenza virus hemagglutinin stalk-reactive antibodies in humans. MBio 7, e01996-15 (2016).

29. Margine, I. et al. H3N2 influenza virus infection induces broadly reactive hemagglutinin stalk antibodies in humans and mice. J. Virol. 87, 4728-4737 (2013). 
30. Krammer, F., Pica, N., Hai, R., Tan, G. S. \& Palese, P. Hemagglutinin stalk-reactive antibodies are boosted following sequential infection with seasonal and pandemic H1N1 influenza virus in mice. J. Virol. 86, 10302-10307 (2012).

31. Wohlbold, T. J. \& Krammer, F. In the shadow of hemagglutinin: a growing interest in influenza viral neuraminidase and its role as a vaccine antigen. Viruses $\mathbf{6}$, 2465-2494 (2014).

32. Easterbrook, J. D. et al. Protection against a lethal H5N1 influenza challenge by intranasal immunization with virus-like particles containing 2009 pandemic H1N1 neuraminidase in mice. Virology 432, 39-44 (2012).

33. Wan, H. et al. Molecular basis for broad neuraminidase immunity: conserved epitopes in seasonal and pandemic $\mathrm{H} 1 \mathrm{~N} 1$ as well as $\mathrm{H} 5 \mathrm{~N} 1$ influenza viruses. J. Virol. 87, 9290-9300 (2013).

34. Chen, Z., Kim, L., Subbarao, K. \& Jin, H. The 2009 pandemic H1N1 virus induces anti-neuraminidase (NA) antibodies that cross-react with the NA of $\mathrm{H} 5 \mathrm{~N} 1$ viruses in ferrets. Vaccine 30, 2516-2522 (2012).

35. Deroo, T., Jou, W. M. \& Fiers, W. Recombinant neuraminidase vaccine protects against lethal influenza. Vaccine 14, 561-569 (1996).

36. Johansson, B. E. \& Kilbourne, E. D. Immunization with purified N1 and N2 influenza virus neuraminidases demonstrates cross-reactivity without antigenic competition. Proc. Natl Acad. Sci. USA 91, 2358-2361 (1994).

37. Monto, A. S. et al. Antibody to influenza virus neuraminidase: an independent correlate of protection. J. Infect. Dis. 212, 1191-1199 (2015).

38. Liang, S., Mozdzanowska, K., Palladino, G. \& Gerhard, W. Heterosubtypic immunity to influenza type A virus in mice. Effector mechanisms and their longevity. J. Immunol. 152, 1653-1661 (1994).

39. Nachbagauer, R. et al. Induction of broadly reactive anti-hemagglutinin stalk antibodies by an H5N1 vaccine in humans. J. Virol. 88, 13260-13268 (2014).

40. Pica, N. et al. Hemagglutinin stalk antibodies elicited by the 2009 pandemic influenza virus as a mechanism for the extinction of seasonal H1N1 viruses. Proc. Natl Acad. Sci. USA 109, 2573-2578 (2012).

41. Krammer, F. \& Palese, P. Influenza virus hemagglutinin stalk-based antibodies and vaccines. Curr. Opin. Virol. 3, 521-530 (2013).

42. Krammer, F. et al. Assessment of influenza virus hemagglutinin stalk-based immunity in ferrets. J. Virol. 88, 3432-3442 (2014).

43. Goff, P. H. et al. Adjuvants and immunization strategies to induce influenza virus hemagglutinin stalk antibodies. PLoS One 8, e79194 (2013).

44. Ryder, A. B. et al. Vaccination with vesicular stomatitis virus-vectored chimeric hemagglutinins protects mice against divergent influenza virus challenge strains. J. Virol. 90, 2544-2550 (2015).

45. van der Most, R. G. et al. Seeking help: B cells adapting to flu variability. Sci. Transl. Med. 6, 246ps8 (2014)
46. van den Brand, J. M. et al. Efficacy of vaccination with different combinations of MF59-adjuvanted and nonadjuvanted seasonal and pandemic influenza vaccines against pandemic H1N1 (2009) influenza virus infection in ferrets. J. Virol. 85, 2851-2858 (2011).

47. Krammer, F. Novel universal influenza virus vaccine approaches. Curr. Opin. Virol. 17, 95-103 (2016)

48. Wrammert, J. et al. Broadly cross-reactive antibodies dominate the human B cell response against 2009 pandemic H1N1 influenza virus infection. J. Exp. Med. 208, 181-193 (2011).

49. Ekiert, D. C. et al. Antibody recognition of a highly conserved influenza virus epitope. Science 324, 246-251 (2009).

50. Ekiert, D. C. et al. A highly conserved neutralizing epitope on group 2 influenza $A$ viruses. Science 333, 843-850 (2011).

51. Sui, J. et al. Structural and functional bases for broad-spectrum neutralization of avian and human influenza A viruses. Nat. Struct. Mol. Biol. 16, 265-273 (2009).

52. Chen, C. J. et al. Influenza A viruses expressing intra- or inter-group chimeric hemagglutinins. J. Virol. 90, 3789-3793 (2016).

53. Garçon, N., Vaughn, D. W. \& Didierlaurent, A. M. Development and evaluation of AS03, an adjuvant system containing a-tocopherol and squalene in an oil-inwater emulsion. Expert Rev. Vaccines 11, 349-366 (2012).

54. Morel, S. et al. Adjuvant System ASO3 containing a-tocopherol modulates innate immune response and leads to improved adaptive immunity. Vaccine 29, 2461-2473 (2011).

55. Margine, I., Palese, P. \& Krammer, F. Expression of functional recombinant hemagglutinin and neuraminidase proteins from the novel H7N9 influenza virus using the Baculovirus Expression System. J. Vis. Exp. 6, e51112 (2013).

56. Krammer, F. et al. A carboxy-terminal trimerization domain stabilizes conformational epitopes on the stalk domain of soluble recombinant hemagglutinin substrates. PLoS One 7, e43603 (2012).

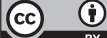

This work is licensed under a Creative Commons Attribution 4.0 International License. The images or other third party material in this article are included in the article's Creative Commons license, unless indicated otherwise in the credit line; if the material is not included under the Creative Commons license, users will need to obtain permission from the license holder to reproduce the material. To view a copy of this license, visit http://creativecommons.org/licenses/ by/4.0/

(c) The Author(s) 2016 